\title{
Psychiatric disorders in candidates for surgery for epilepsy
} Rahul Manchanda, Betsy Schaefer, Richard S McLachlan, Warren T Blume,
Samuel Wiebe, John P Girvin, Andrew Parrent, Paul A Derry

\begin{abstract}
Objective-To provide a descriptive analysis of the prevalence and pattern of psychiatric morbidity among 300 consecutive epileptic patients refractive to treatment and admitted during a six year period for evaluation of their candidature for surgery.

Methods-Patients underwent detailed observation of their seizure and standardised psychiatric assessment. Patients were considered to be refractory to treatment if they continued to manifest seizures with an average frequency of at least once every month even with polytherapy using up to three different anticonvulsants for a period of at least two years. Of the 300 patients, 231 had a temporal lobe focus, 43 had a non-temporal lobe focus, and 26 patients had a generalised and multifocal seizure onset.

Results and conclusions-With the DSMIII-R criteria $142(47 \cdot 3 \%)$ patients emerged as psychiatric cases. A principal axis $I$ diagnosis was made in $88(29.3 \%)$, and an axis II diagnosis (personality disorder) in another $54(18 \cdot 0 \%)$ patients. The most common axis $I$ diagnosis was anxiety disorders $(10 \cdot 7 \%)$. A schizophrenialike psychosis was seen in $13(4 \cdot 3 \%)$. Most patients with personality disorders showed dependent and avoidant personality traits. There was a significantly higher psychotic subscore on the present state examination in the temporal than with the non-temporal group of patients. These findings were not significant when compared with patients with a generalised and multifocal seizure disorder. There were no significant findings between the different seizure focus groups on the neurotic subscores. The findings with regard to laterality of seizure focus and the neurotic or psychotic subscores were not significant.
\end{abstract}

(F Neurol Neurosurg Psychiatry 1996;61:82-89)

Keywords: psychiatric disorders; surgery for epilepsy

Surgical treatment for patients with refractory epilepsy has become common since the pioneering work of Horsley.' Resection of the seizure focus or corpus callosotomy to prevent interhemispheric spread of the seizure activity are the most common procedures. The largest number of epilepsy surgery operations have been performed on patients with temporal lobe epilepsy.

The standard of psychiatric assessment in the units carrying out surgery for epilepsy varies widely. At the first Palm Desert workshop of centres carrying out surgery for epilepsy, it was concluded that psychiatric investigation of patients in epilepsy surgery programmes left much to be desired. ${ }^{2}$ At the most recent Palm Desert workshop, there was general consensus that each patient should have a social and psychiatric care programme with set goals determined before surgery and the patient's progress and relationship to this plan should be evaluated after surgery.

Psychiatric problems after temporal lobectomy have been reported in many series. +12 Considerable attention has also been focused on specific disorders such as interictal schizophrenia-like psychosis ${ }^{13}{ }^{17}$ and depression. ${ }^{18}{ }^{22}$ However, studies describing the pattern of psychiatric disorders among consecutive patients undergoing assessments in an epilepsy investigations unit or those assessed presurgically are lacking. "111 Even though Bladin $^{12}$ reports that extensive preoperative psychiatric data, including DSM-III diagnosis were available in his series of 115 temporal lobectomy patients, no such information is presented.

The epilepsy unit at University Hospital, London, Canada was formally opened in May, 1986 to investigate and treat patients with medically refractory seizure disorder and particularly to determine if resective surgery or corpus callosatomy would help. We first carried out a pilot study ${ }^{23}$ to examine the prevalence of psychopathology in 71 consecutive patients with intractable epilepsy to determine if routine psychiatric assessments were warranted. Using the general health questionnaire (GHQ), a self rated 60 item measure of psychopathology, ${ }^{2+} 45 \%$ of patients were identified as psychiatric cases. This, in our opinion, was a psychiatric morbidity high enough to warrant the development of a comprehensive psychiatric consultation liaison service for the epilepsy unit. In addition to providing a clinical service, detailed research evaluation of the range of psychopathology in this sample is carried out.

This report provides a descriptive analysis of the prevalence and pattern of psychiatric morbidity among 300 consecutive patients admitted to the epilepsy investigation unit for evaluation of their surgical candidature. To the best of our knowledge, this is the largest series of its kind. 


\section{Method}

The sample for this study was drawn from consecutive adult (16 and over) patients refractory to treatment for epilepsy admitted to the epilepsy unit during a six year period (1989-94). Patients are considered to be refractory to treatment if they continue to manifest seizures with an average frequency of at least once every month, even with polytherapy using up to three different anticonvulsants for a period of at least two years. All patients have, therefore, been in treatment and investigated extensively before being sent to the epilepsy unit for assessment of their surgical candidature. ${ }^{25}$ All patients underwent clinical observation of the seizure phenomena. The type of seizure activity was categorised by an epileptologist (WTB; RSM; SW) according to the classification of the International League Against Epilepsy. ${ }^{26}$ All patients had standard EEG telemetry with scalp electrodes with continuous monitoring until sufficient seizures were recorded to delineate the focus. When scalp recordings failed to do this, then telemetry was continued with implanted subdural electrodes. This provided the epileptologist with as much certainty as possible of the type of epilepsy and of the seizure focus. In addition, all patients had a detailed clinical assessment by a psychiatrist (RM), who was not aware of the exact seizure focus in these patients at the time of assessment. All patients were informed of the purpose of assessment and the research component to data collection. The project was approved by the ethics committee of the University of Western Ontario. A written consent for participation was also obtained. The method used for evaluation was as follows:

SOCIODEMOGRAPHIC AND CLINICAL VARIABLES The group comprised 300 consecutive patients admitted to the epilepsy investigation unit at University Hospital. The sociodemographic and clinical variables recorded were age, sex, marital, employment, and living status. The seizure variables included age of onset, duration, frequency, time of occurrence, and family history of seizures. Also noted were patient and family history of psychiatric disorder and previous psychiatric contact if any. A history of physical or sexual abuse and trouble with the law was also recorded.

\section{PSYCHIATRIC INTERVIEW AND HISTORY}

The Palm Desert workshop emphasised that psychiatric diagnosis is important and recommended using an international classification system as a standard practice in all units. According to a census of psychiatric availability, it was reported that although $73 \%$ of the replying units indicate use of a psychiatric assessment protocol, only $44 \%$ used DSM-III or ICD-9 for psychiatric diagnosis. All units were willing to use a standardised psychiatric assessment, if psychiatric expertise was available. The Europeans tended to prefer ICD-9 and the Americans DSM-III-R. ${ }^{3}$

All patients in this study had a detailed psy- chiatric interview, which included a history of present and past complaints, personal, social, and family history, and mental state examination. This was carried out to arrive at a diagnosis based on the DSM-III-R criteria. ${ }^{27}$ Information obtained from the structured clinical interview, present state examination ${ }^{28}$ (see below) was also used to assist in the diagnostic process. The DSM-III-R provides descriptions of diagnostic categories of various mental disorders. A multi-axial evaluation permits each case to be assessed on several "axes", each of which refers to a different class of information. There are five axes in the DSM-III-R multiaxial classification. The first three axes constitute the official diagnostic assessment. Use of the DSM-III-R multiaxial system ensures that attention is given to certain types of disorders, aspects of the environment, and areas of functioning that might be overlooked if the focus were on assessing a single presenting problem. Axis I refers to the clinical syndromes and axis II refers to the personality disorders. The separation between axis I and axis II ensures that in the evaluation of adults, consideration is given to the possible presence of personality disorders that may be overlooked when attention is directed to the usually more florid axis I disorder. In many instances, there is a disorder on both axes. When a person receives more than one diagnosis, the principal diagnosis is the condition that was the main focus of attention or treatment at the time of evaluation. Axis III permits the clinician to indicate any current physical disorder or condition that is potentially relevant to the understanding or management of the case. All patients in this study had an axis III diagnosis of epilepsy.

\section{PRESENT STATE EXAMINATION ${ }^{28}$}

The present state examination (PSE) consists of a structured clinical interview for ascertaining the presence of various psychiatric symptoms. It consists of 140 items, which systematically cover all the phenomena likely to be relevant when conducting a mental state examination. An important feature is that, although certain initial questions are compulsory, the onus is on the interviewer to carry out clinical cross-examination to establish the presence or absence of a symptom according to the criteria listed in the glossary for each symptom. There is a system of cut off points following obligatory questions, so that the interviewer can move on to another group of symptoms if he considers that there are no symptoms in a particular area. The items are grouped into sections to facilitate the conduct of the interview. Some items are rated on the basis of frequency of occurrence and some on the severity. Most items are rated on a combination of the two $(1=$ occasional or not severe, $2=$ continuous or severe). The score sheet is completed during the interview, so that the rater is not left to trust his memory for such a comprehensive scale. The principal investigator (RM) has been trained in the use of the PSE and is a practised rater. As recommended, the time interval for the presence or absence of symptoms was the month preceding the assessment. 
Table 1 Sociodemographic and clinical characteristics $(n=300)$

\begin{tabular}{|c|c|c|c|}
\hline & \multicolumn{3}{|l|}{ Seizure focus } \\
\hline & $\begin{array}{l}\text { Temporal } \\
(n=231)\end{array}$ & $\begin{array}{l}\text { Non-temporal } \\
(n=43)\end{array}$ & $\begin{array}{l}\text { Generalised } \\
(n=26)\end{array}$ \\
\hline Age (mean (SD)) & $31 \cdot 85(9 \cdot 60)$ & $29 \cdot 05(8 \cdot 86)$ & $27 \cdot 92(8 \cdot 04)$ \\
\hline \multicolumn{4}{|l|}{ Sex: } \\
\hline Men & 116 & 24 & 13 \\
\hline Women & 115 & 19 & 13 \\
\hline \multicolumn{4}{|l|}{ Marital status: } \\
\hline Single & 110 & 25 & 19 \\
\hline Married & 96 & 14 & 5 \\
\hline Others & 25 & 4 & 2 \\
\hline Age of onset (mean (SD)) & $12.88(10.09)$ & $12 \cdot 33(7 \cdot 19)$ & $12.73(8.00)$ \\
\hline Duration (mean (SD)) & $19.09(10.32)$ & $16 \cdot 67(9 \cdot 11)$ & $15 \cdot 31(8 \cdot 91)$ \\
\hline $\begin{array}{l}\text { Number of seizures } \\
\text { per month (mean (SD)) }\end{array}$ & $20.63(36.86)$ & $23 \cdot 81(43.50)$ & $24 \cdot 64(41 \cdot 52)$ \\
\hline
\end{tabular}

There were no statistically significant differences between the three groups.

The between rater reliability of the PSE has been studied extensively ${ }^{29}{ }^{30}$ and studies have shown high levels of rater agreement for the instrument within a single centre, between centres, and between psychiatrists. ${ }^{31}{ }^{32}$ The main practical limitation of the PSE is the difficulty in completing the full scale with patients who are disturbed, uncooperative, or uncommunicative. Also, minor psychopathology at assessment may be missed because of the high threshold for rating the PSE. However, this would ensure that there is a significant psychopathology in the patients who rate positively on the different items of the PSE. The routine statistical output (using the CATEGO program) provides symptoms and syndrome profiles, subscores and a total score, and a classification into categories which are highly concordant with an ICD clinical diagnosis. Symptoms are combined in the first stage of the CATEGO program to form 38 syndromes. Four subscores are derived from summing up the ratings on appropriate symptoms ${ }^{32}$ as follows: delusional and hallucinatory syndromes (DAH); behavioural, speech and other syndromes (BSO); specific neurotic syndromes (SNS); non-specific neurotic syndromes (NSN). Knights et $a b^{33}$ combined $\mathrm{DAH}$ and BSO to derive a psychotic subscore and SNR and NSN to derive a neurotic subscore. The widespread use of the PSE in different countries helps bring uniformity and clarity into diagnosis and descriptive psychopathology.

Table 2 Epilepsy and psychopathology: DSM-III-R diagnosis $(n=300)$

\begin{tabular}{lcccr}
\hline & $\begin{array}{l}\text { Temporal } \\
(n=231)\end{array}$ & $\begin{array}{l}\text { Non } \\
\text { temporal } \\
(n=43)\end{array}$ & $\begin{array}{l}\text { Generalised } \\
(n=26)\end{array}$ & $\begin{array}{l}\text { Total } \\
\text { sample } \\
(n=300)\end{array}$ \\
\hline No psychiatric disorder & $127(55)$ & $19(44 \cdot 2)$ & $12(46 \cdot 2)$ & $158(52 \cdot 7)$ \\
Psychiatric disorder & $104(45)$ & $24(55 \cdot 9)$ & $14(53 \cdot 8)$ & $142(47 \cdot 3)$ \\
Axis II personality disorder & $43(18 \cdot 6)$ & $6(14 \cdot 0)$ & $5(19 \cdot 2)$ & $54(18 \cdot 0)$ \\
Axis I & $61(26 \cdot 4)$ & $18(41 \cdot 9)$ & $9(34 \cdot 6)$ & $88(29 \cdot 2)$ \\
Anxiety disorders & $23(10 \cdot 0)$ & $7(16 \cdot 3)$ & $2(7 \cdot 7)$ & $32(10 \cdot 7)$ \\
Schizophrenia & $10(4 \cdot 3)$ & $1(2 \cdot 3)$ & $2(7 \cdot 7)$ & $13(4 \cdot 3)$ \\
Mood disorders & $7(3 \cdot 0)$ & $2(4 \cdot 7)$ & & $9(3 \cdot 0)$ \\
Adjustment disorder & $4(1 \cdot 7)$ & $3(7 \cdot 0)$ & & $7(2 \cdot 3)$ \\
Impulse control disorder & $2(0 \cdot 9)$ & $4(9 \cdot 3)$ & $3(11 \cdot 5)$ & $6(2 \cdot 0)$ \\
Substance misuse & $7(3 \cdot 0)$ & & & $4(3 \cdot 3)$ \\
OMS with psychosis & $4(1 \cdot 7)$ & $1(2 \cdot 3)$ & & $3(1 \cdot 3)$ \\
OMS without psychosis & $2(0 \cdot 9)$ & $1(7 \cdot 3)$ & $2(7 \cdot 7)$ & $4(1 \cdot 3)$ \\
Conversion disorder & $2(0 \cdot 9)$ & &
\end{tabular}

Values are numbers of patients (\%). There were no statistically significant differences in the diagnostic type between patients with a temporal or non-temporal seizure focus or a generalised seizure disorder.

\section{Results}

GENERAL DEMOGRAPHICS (TABLE 1)

A total of 300 consecutive patients was assessed in the epilepsy unit during a period of six years. There were 147 women $(49.0 \%)$, and 153 men $(51.0 \%)$. The mean age was 31 (SD 9.44) years with a range of 16 to 61 years. Marital status was: single $154(51 \cdot 3 \%)$ and married $115(38 \cdot 3 \%)$. There were 159 $(53.0 \%)$ living on their own and $141(47.0 \%)$ with their parent/s. The mean age of onset of epilepsy was 12.79 (SD 9.54) and mean duration of epilepsy was 18.42 (SD 10.09) years. The mean frequency of seizures per month in the preceding year was 21.43 (SD 38.17). There was a family history of epilepsy in 89 $(29.7 \%)$ and psychiatric illness in 117 (39.0\%). Dexterity was right in $238(79.3 \%)$, left in $43(14.3 \%)$, and $16(5.3 \%)$ were ambidextrous.

The focus of seizure onset was determined by telemetry using surface or subdural electrodes. Of the 300 patients 231 had a temporal lobe focus (116 left temporal lobe, 93 right temporal, and 22 bitemporal focus), 43 had a non-temporal focus, and in 26 patients there was no definite seizure focus. This last group consisted of patients with generalised, widespread, bilateral, or multifocal epileptiform abnormalities on EEG. The primary type of seizure in these patients was as follows: complex partial $146(48 \cdot 7 \%)$, simple/complex partial with secondary generalised $93(31 \cdot 1 \%)$, complex and simple partial $26(8 \cdot 7 \%)$, primary generalised $20(6 \cdot 7 \%)$, simple partial 12 $(4.0 \%)$, and no seizure disorder detected one $(0 \cdot 3 \%)$.

\section{PSYCHIATRIC DIAGNOSIS}

Using the DSM-III-R criteria, $142(47 \cdot 3 \%)$ patients emerged as psychiatric cases. A principal diagnosis on axis I was made in 88 (29.3\%) patients and an axis II diagnosis (personality disorder) in another $54(18.0 \%)$. Table 2 shows the different diagnosis in the three groups of patients. The most common axis I diagnosis was anxiety disorders $(10 \cdot 7 \%)$. The word "neurosis" has been deleted from the official nomenclature, and the division among the various anxiety disorders has been made on the basis of valid and reliably recognisable clinical criteria. Anxiety disorders refer to pathological anxiety states, which are an inappropriate response to a given stimulus by virtue of either its intensity or its duration. This group of disorders includes panic disorder with or without agoraphobia, social phobia, generalised anxiety disorder, and obsessive-compulsive disorder.

The distribution of other psychiatric disorders was as follows: schizophrenia $13(4 \cdot 3 \%)$, mood disorders nine $(3.0 \%)$, adjustment disorder seven $(2 \cdot 3 \%)$, organic brain syndrome seven $(2 \cdot 3 \%)$, impulse control disorder six $(2.0 \%)$, substance misuse $10(3.3 \%)$, and conversion disorder (pseudoseizures) four (1.3\%).

An axis II diagnosis of personality disorders was made in $54(18 \%)$ of our sample. Personality disorders refer to behaviours or traits that are characteristic of the persons' 
Table 3 Epilepsy and psychopathology: present state examination CATEGO classes

\begin{tabular}{lcccc}
\hline & $\begin{array}{l}\text { Total } \\
\text { sample } \\
(n=292)\end{array}$ & $\begin{array}{l}\text { Temporal } \\
\text { lobe } \\
(n=225)\end{array}$ & $\begin{array}{l}\text { Non- } \\
\text { temporal } \\
(n=42)\end{array}$ & $\begin{array}{l}\text { Generalised } \\
(n=25)\end{array}$ \\
\hline No psychiatric disorder & $157(53 \cdot 8)$ & $117(52 \cdot 0)$ & $24(57 \cdot 1)$ & $16(64 \cdot 0)$ \\
Psychiatric disorder & $135(46 \cdot 2)$ & $108(48 \cdot 0)$ & $18(42 \cdot 9)$ & $9(36 \cdot 0)$ \\
Anxiety states & $61(20 \cdot 9)$ & $43(19 \cdot 1)$ & $12(28 \cdot 6)$ & $6(24 \cdot 0)$ \\
Neurotic depression & $30(10 \cdot 3)$ & $25(11 \cdot 1)$ & $4(9 \cdot 5)$ & $1(4 \cdot 0)$ \\
Schizophrenic psychoses & $11(3 \cdot 7)$ & $10(4 \cdot 4)$ & & $1(4 \cdot 0)$ \\
Obsessional neurosis & $7(2 \cdot 3)$ & $7(3 \cdot 1)$ & & \\
Hysteria & $1(0 \cdot 3)$ & $1(0 \cdot 4)$ & & \\
Uncertain psychosis & $8(2 \cdot 7)$ & $8(3 \cdot 6)$ & $1(2 \cdot 4)$ & \\
Paranoid psychosis & $8(2 \cdot 7)$ & $7(3 \cdot 1)$ & $1(2 \cdot 4)$ & \\
Depressive psychosis & $3(1 \cdot 0)$ & $3(1 \cdot 3)$ & & $1(4 \cdot 0)$ \\
Manic psychoses & $2(0 \cdot 7)$ & $2(0 \cdot 9)$ & & \\
Retarded depression & $4(1 \cdot 3)$ & $2(0 \cdot 9)$ & & \\
\hline
\end{tabular}

Values are numbers of patients (\%). There were no statistically significant differences in the CATEGO classes between patients with a temporal or non-temporal seizure focus or a generalised seizure disorder. recent and long term functioning and cause either significant impairment in social or occupational functioning, or subjective distress. Behaviours or traits limited to episodes of illness are not considered in making a diagnosis of personality disorder. Most of our cases did not meet criteria for a specific subtype of personality disorder and often showed dependent and avoidant personality traits.

Based on the CATEGO classes derived from the PSE, a total of $135(46 \cdot 2 \%)$ patients received a psychiatric diagnosis (table 3 ). The commonest psychiatric disorders based on this schedule were anxiety states $61(20.9 \%)$ and neurotic depression 30 (10.3\%). Other psychiatric disorders were as follows: schizophrenic psychosis $11(3 \cdot 7 \%)$, paranoid psychosis eight

Table 4 Psychiatric symptoms and seizure focus

\begin{tabular}{lccc}
$\begin{array}{l}\text { PSE } \\
\text { syndromes }\end{array}$ & $\begin{array}{l}\text { Temporal } \\
\text { focus } \\
(n=225)\end{array}$ & $\begin{array}{l}\text { Non-temporal } \\
\text { focus } \\
(n=42)\end{array}$ & $\begin{array}{l}\text { Generalised } \\
(n=25)\end{array}$ \\
\hline Worrying & $146(69 \cdot 9)$ & $25(59 \cdot 5)$ & $22(88 \cdot 0)$ \\
Loss of interest/concentration & $99(44 \cdot 0)$ & $19(45 \cdot 3)$ & $10(40 \cdot 0)$ \\
Irritability & $94(41 \cdot 8)$ & $23(54 \cdot 8)$ & $5(20 \cdot 0)$ \\
Social unease & $89(39 \cdot 6)$ & $10(23 \cdot 8)$ & $8(32 \cdot 0)$ \\
Ideas of reference & $78(34 \cdot 7)$ & $10(23 \cdot 8)$ & $5(20 \cdot 0)$ \\
Somatic symptoms of depression & $70(31 \cdot 2)$ & $12(28 \cdot 5)$ & $5(20 \cdot 0)$ \\
Lack of energy & $60(26 \cdot 7)$ & $11(26 \cdot 2)$ & $11(44 \cdot 0)$ \\
Tension & $57(25 \cdot 3)$ & $11(26 \cdot 2)$ & $8(32 \cdot 0)$ \\
Special features of depression & $55(24 \cdot 4)$ & $8(19 \cdot 1)$ & $6(24 \cdot 0)$ \\
Situational anxiety & $44(19 \cdot 5)$ & $11(26 \cdot 1)$ & $6(24 \cdot 0)$ \\
General anxiety & $22(14 \cdot 2)$ & $7(16 \cdot 6)$ & $5(20.0)$ \\
Depressed mood & $18(8 \cdot 0)$ & $11(26 \cdot 2)$ & $2(8 \cdot 0)$ \\
Obsessional syndrome & $16(7 \cdot 1)$ & $4(9 \cdot 5)$ & 0 \\
Non-specific psychosis & $14(6 \cdot 2)$ & $1(2 \cdot 4)$ & $1(4 \cdot 0)$ \\
Organic impairment & $12(5 \cdot 3)$ & $1(4 \cdot 8)$ & $2(8 \cdot 0)$ \\
Delusions of reference & $9(4 \cdot 0)$ & 0 & $1(4 \cdot 0)$ \\
Auditory halluciations & $6(2 \cdot 7)$ & 0 & $1(4 \cdot 0)$ \\
\hline
\end{tabular}

Values (numbers of patients (\%)) are for the most frequently occurring symptom clusters out of 38 syndromes based on the present state examination. There were no statistically significant differences based on the seizure focus.

Table 5 Psychiatric symptoms and seizure focus

\begin{tabular}{llll}
\hline & $\begin{array}{l}\text { Temporal } \\
(n=225)\end{array}$ & $\begin{array}{l}\text { Non-temporal } \\
(n=42)\end{array}$ & $\begin{array}{l}\text { Generalised } \\
(n=25)\end{array}$ \\
\hline $\begin{array}{l}\text { Delusional and hallucinatory } \\
\text { syndromes (DAH) }\end{array}$ & $0.42(1 \cdot 78)$ & $0.07(0.46)$ & $0.28(1.40)$ \\
$\begin{array}{l}\text { Behavioural, speech, and other } \\
\text { syndromes (BSO) }\end{array}$ & $0.39(1.23)$ & $0.12(0.63)$ & $0.32(1.60)$ \\
$\begin{array}{l}\text { Psychotic subscore } \\
\text { Specific neurotic syndromes } \\
\text { (SNR) }\end{array}$ & $0.81(2.60)$ & $0.19(1.09)$ & $0.60(3.00)$ \\
$\begin{array}{l}\text { Non-specific neurotic (NSN) } \\
\text { Neurotic subscore }\end{array}$ & $\begin{array}{l}1.55(2.21) \\
7 \cdot 59(4 \cdot 69)\end{array}$ & $\begin{array}{l}1.62(2.23) \\
4.98(4 \cdot 4)\end{array}$ & $\begin{array}{l}1.40(2.0) \\
6.00(7.73)\end{array}$ \\
\hline
\end{tabular}

Values are mean (SD). The 38 syndromes on the PSE were further categorised into the DAH and BSO (psychotic subscore) and the SNR and NSN (neurotic subscore). There were signifi-
cant differences between the temporal and non-temporal seizure focus groups on psychotic $(P=$ cant differences between the temporal and non-temporal seizure focus groups on psychotic $(P=$
$0.01)$ scores, DAH $(P=0.01)$ and BSO $(P=0.03)$ but not on the neurotic scores. There were no $0.01)$ scores, DAH $(P=0.01)$ and BSO (P $=0.03)$ but not
significant findings based on the laterality of seizure focus.
$(2 \cdot 7 \%)$, uncertain psychosis eight $(2 \cdot 8 \%)$, obsessional neurosis seven $(2 \cdot 3 \%)$, depressive psychosis three $(1 \cdot 0 \%)$, retarded depression four $(1 \cdot 3 \%)$, manic psychosis two $(0 \cdot 7 \%)$, and hysteria one $(0 \cdot 3 \%)$. It should be noted that the PSE is not well suited to evaluate the category of personality disorders which cannot be evaluated on the basis of recording of symptomatology alone. It is possible that a number of patients who were diagnosed with a personality disorder on the basis of the DSM-III-R received a diagnosis of anxiety states or neurotic depression because of a degree of subjective distress at the time of evaluation. This would seem likely because of the discrepancy in the prevalence of anxiety disorders in $10.7 \%$ of patients based on the DSM-III-R and $20.9 \%$ based on the PSE.

\section{PSYCHOPATHOLOGY AND SEIZURE FOCUS}

The individual item ratings on the 140 item PSE were computed to arrive at 36 syndrome profiles. Table 4 shows the more commonly rated PSE syndromes based on the seizure focus. The highest ratings were on the syndromes of worrying, loss of interest/concentration, irritability, social unease, and ideas of reference. Given the relative infrequency of some of these ratings, the 38 syndromes were further categorised into the specific neurotic syndromes and non-specific neurotic syndromes leading to a neurotic subscore and a delusional and hallucinatory syndrome and behaviour, speech, and other syndromes leading to the psychotic subscore (table 5). There was a significant difference between the temporal and non-temporal groups on the delusional and hallucinatory syndrome $(P<0.01)$, behavioural speech and other syndromes $(P<0.05)$, and the psychotic subscore $(P<0.01)$. These findings were not significant when compared with patients with a generalised seizure focus. Also, the comparison between seizure focus and the neurotic subscores was not significant. Further statistical analysis was carried out to compare the ratings on the above syndromes and the laterality of seizure focus. These findings were also nonsignificant.

\section{Discussion}

There has generally been an agreement that psychopathology is overrepresented in epileptic populations. Surveys of unselected populations $^{34-36}$ as well as specialised clinic samples ${ }^{23} 37^{-40}$ disclose a considerable excess of psychopathology in patients with epilepsy. Candidates for surgery for epilepsy form a special group of such patients. However, the prevalence and pattern of psychiatric disturbance tend to vary across studies. Walker and Blumer ${ }^{11}$ reported that $32 \%$ of their sample required admission to psychiatric hospital, whereas Jenkins and Larsen ${ }^{10}$ reported that only $8 \%$ of their sample were psychiatrically normal.

The present study is in keeping with the need for comprehensive psychiatric assessments for all candidates for surgery for 
epilepsy and is the largest series to date. As more centres across the world undertake surgery for epilepsy, it is important to have some idea of the kinds of psychiatric problems likely to be encountered during the assessment for surgical candidature. This cohort of candidates for epilepsy surgery was formed through a process of extensive outpatient investigation and careful selection of treatment refractory patients. It is representative of patients deemed suitable for consideration for epilepsy surgery and forms a subset of a larger group of patients with chronic treatment refractory epilepsy. Thus our findings cannot be generalised to epilepsy at large. Further, patients are more likely to be admitted if a focal onset of seizures is suspected during their outpatient evaluation and follow up. Also, they should be considered cooperative with assessment and monitoring. Patients are not denied admission because of a specific psychiatric disorder. Our sample is large ( $\mathrm{n}=300)$ and used standardised diagnostic criteria such as the PSE and the DSM-III-R. Further, the patients studied in this group had extensive documentation on their seizure variables and as much certainty as possible as to their seizure focus. The present investigation also provides a database for comparison with postoperative psychiatric morbidity.

In this study, nearly half of the patients $(47 \cdot 3 \%)$ had evidence of a psychiatric disorder. Axis I diagnosis was made in $88(29.3 \%)$ and axis II disorder in $54(18.0 \%)$. This is lower than in previous studies. In a recent study of patients with complex partial seizures, ${ }^{41}$ a lifetime prevalence of axis I diagnosis was found in $70 \%$ and axis II disorder in $18.3 \%$, giving a total lifetime prevalence of $88.3 \%$. Blumer et al ${ }^{18}$ studied 97 consecutive patients admitted to an epilepsy monitoring unit and found that $65 \%$ had a psychiatric morbidity. In a study of 100 consecutive temporal lobe epileptic patients, ${ }^{6}$ the prevalence of psychiatric disorders was $87 \%$. The patients were categorised as normal $(n=13)$, neurotic $(n=30)$, psychopathic $(n=48)$, psychotic ( $n$ $=16)$ or of epileptic personality $(n=5)$. In 12 patients, two diagnoses were made. In the neurotic group, 17 patients were considered depressed and 22 patients had one or the other form of anxiety disorders. In the psychotic group, eight had schizophreniform psychosis as described by Hill ${ }^{42}$ and Pond. ${ }^{43}$ This would correspond to the schizophrenia like psychosis of epilepsy. ${ }^{44}$ Our PSE findings of anxiety states in $20.9 \%$ and neurotic depression in $10.3 \%$ of patients are comparable with those of Taylor. ${ }^{6}$ Based on the DSM-III-R classification, $16 \%$ of patients had a diagnosis of anxiety disorders, mood disorders, and adjustment disorders. A total of $13(4 \cdot 3 \%)$ patients presented with a schizophrenia like psychosis. Another four $(1.3 \%)$ had an organic psychosis. Overall, $6.0 \%$ of patients with a temporal lobe focus and $7 \cdot 7 \%$ of patients with a generalised seizure disorder had a psychotic illness at the time of assessment. The $5 \cdot 6 \%$ overall prevalence of psychotic illness is comparable with many studies. In a recent review, Trimble ${ }^{45}$ concluded that when the outliers are excluded, the prevalence of psychosis in epilepsy ranges from $2 \cdot 4 \%$ to $8 \%$.

Personality disorders were diagnosed in 54 $(18 \%)$ of our patients. Most of these patients did not meet the criteria for a specific type of DSM-III-R axis II disorder, but there was significant personality dysfunction to justify this diagnosis. We did not see socalled "epileptic personality" with features of hypergraphia, hyperreligiosity, increased philosophical interest, and altered sexuality as reported in earlier studies. ${ }^{64677}$ This impression is based on the clinical interview and utilisation of the DSMIII-R criteria for personality disorders. It was limited by the fact that the PSE is not suited for the investigation of personality disorders. Taylor ${ }^{6}$ considered his patients to be psychopathic $(48 \%)$ if they had a character disorder as well as aggressive and rude behaviour. The term "epileptic personality" ( $n=5)$ was used in extremes of religiosity or stickiness or arrogant personality. Four of these patients were also included in other categories. Taylor also used various adjectives for psychopathic disorders-for example, aggressive (27\%), immature or inadequate $(15 \%)$, paranoid $(7 \%)$, antisocial $(6 \%)$, cyclothymic $(4 \%)$, schizoid (3\%), and sexual deviations (2\%). Most of these patients would not fit into a modern psychiatric diagnostic criteria. Most of our patients had personality traits of dependent and avoidant type.

The association between epilepsy and psychopathology has been discussed for many years, and over time there has generally been an agreement that psychopathology is overrepresented in epileptic populations. ${ }^{48}$ Our study in a selected population of treatment refractory epileptic patients admitted for investigation of their surgical candidature also supports this hypothesis. However, the controversy as to whether or not psychiatric disturbance is related to the type of epilepsy continues to persist. We failed to confirm that patients with focal epilepsy, particularly deriving from the temporal lobes, show more psychopathology than those with a generalised seizure disorder or with a non-temporal seizure focus. Interestingly, when we looked at specific psychiatric symptomatology based on standardised rating criteria of the PSE, we found that patients with a temporal lobe seizure focus had significantly higher psychotic symptomatology than those with a non-temporal seizure focus. There was no significant difference on psychotic subscore between the temporal lobe group and patients with a generalised seizure disorder. This is probably due to the presence of one psychotic patient in the generalised seizure disorder group. Patients with temporal lobe seizure focus, however, did not rate significantly higher on the neurotic syndromes when compared with non-temporal lobe focus or a generalised seizure disorder (table 5). Several investigators ${ }^{38} 39$ 49-56 found no difference in the incidence of various psychiatric disorders in different types of epilepsies. Others, however, have reported a very increased incidence of psychiatric disorders in 
patients with temporal lobe epilepsy compared with those with other types of the illness. ${ }^{57-68}$

The role of the temporal lobe in the development of psychosis in epilepsy has been a matter of considerable disagreement in the medical literature. A classification system for psychosis in epilepsy should ideally consider psychopathology, duration, and course of psychosis, type of epilepsy, relation to seizure activity, drug treatment, EEG findings, and psychosocial factors. ${ }^{15}$ Variations in phenomenology and precipitation can also be seen between patients who experience recurrent psychotic episodes. ${ }^{69-70}$ The usefulness of both clinical application and research purposes of previously proposed syndromatic classification systems $^{71-74}$ is therefore limited. Rather than looking at the type of psychotic disorder based on a diagnostic system, we looked at psychotic symptomatology presented by our patient population. It is widely accepted that psychoses are positively linked to temporal lobe epilepsy ${ }^{3744}$ but this has not been confirmed unequivocally by controlled studies. ${ }^{75}$ Several controlled studies have shown that psychotic disorders are no less frequent in generalised epilepsies than in temporal lobe epilepsies. ${ }^{38396776-80}$ Our findings are similar. However, when we examined the presence of any psychotic symptoms based on PSE ratings, patients with a temporal lobe seizure focus had a significantly higher psychotic subscore than patients with non-temporal focus (table 5). There are other studies which show an increased risk for psychosis in temporal lobe epilepsy compared with generalised epilepsies. ${ }^{406879}$ Results from studies to date suggest that (a) psychoses are rare complications in a group of patients with epilepsy, (b) patients with epilepsy and psychosis are overrepresented in special centres, and (c) there is a link between more severe and more "Schneiderian" psychoses and temporal lobe epilepsy compared with generalised epilepsy. Our study would support this conclusion. The strongest risk factors for psychosis and epilepsy are long duration of epilepsy, ${ }^{60}$ multiple seizure types, ${ }^{727981-85}$ and poor response to drug treatment. ${ }^{8185}$ All our patients were refractory to treatment. Further, the mean duration of epilepsy in patients with a psychotic disorder was $24 \cdot 3$ years compared with the mean duration of 18.4 years in the total sample.

Substantial evidence indicates that patients with epilepsy experience a higher rate of depressive symptoms ${ }^{22}{ }^{86}$ than do non-epileptic patients with the same degree of disability. ${ }^{20}$ These findings have been reported both in patients with primary generalised epilepsy and those with complex partial seizures of temporal lobe origin. ${ }^{7877}$ In a recent study, ${ }^{88}$ of 53 patients with medically intractable complex partial seizures, $33(62 \%)$ had a history of interictal depressive disorders, $16(30 \%)$ of whom met criteria for one or more major depressive episodes. Based on the DSM-III-R diagnosis, only nine $(3 \%)$ of our patients had a diagnosis of a mood disorder and another seven $(2.3 \%)$ patients had a diagnosis of an adjustment disorder. On the basis of the PSE, $30(10 \cdot 3 \%)$ patients had a neurotic depression. Other diagnoses consisted of depressive psychosis three $(1.0 \%)$, retarded depression four $(1 \cdot 3 \%)$, and manic psychosis two $(0 \cdot 7 \%)$, making a total of $39(13 \%)$ for mood disorders. The prevalence of depression in our patients is much lower than those seen in other studies. One explanation may be that our findings are point prevalence of depression as opposed to lifetime prevalence. Further, it may be argued that on admission to an epilepsy monitoring unit, the entire focus is on the seizures and the patients may not mention complaints of an emotional nature. Depressive symptoms in evidence may therefore be viewed as reasonable reaction to a difficult chronic disorder. We would argue against this, as all patients were clinically evaluated in detail and were observed for several days by the nursing staff. On the other hand, our patients wait for about a year before admission to the unit and are unlikely to refuse admission because of emotional difficulties such as depression. Also, they may be more hopeful than at any other time because of the possibility of relief from their chronic disorder.

There was a high prevalence of epilepsy in family members $(29 \cdot 7 \%)$. Such a familial predisposition has been well documented in generalised epilepsy and even in focal epilepsy. ${ }^{89}$ The potential impact of epilepsy on the family is difficult to gauge and likely to be variable. The prevalence of psychiatric disorders in the first degree relatives of our patient sample was also high (39\%). In an epidemiological study, Rutter and colleagues ${ }^{90}$ reported that one fifth of mothers of children with epilepsy had a history of nervous breakdown. Hoare ${ }^{11}$ reported an association between psychiatric disturbance in the child with chronic epilepsy and increased psychiatric morbidity in the mother. It was proposed that if a child continues to have epilepsy, it may adversely affect the psychological health of the mother. Bagley ${ }^{92}$ reported a similar finding of increased emotional distress in mothers of children presenting with more disturbed behaviour. Further, higher levels of anxiety and depression were reported in the main caretakers of patients with epilepsy ${ }^{93}$ compared with those reported in general medical outpatients and within the general population. The group of patients in our sample are highly selected, with a long duration of epilepsy refractory to treatment. These patients and their immediate family members are a particularly vulnerable group.

The phenomenology experienced by the patients with a seizure disorder is comparable with those patients with a psychiatric disorder but without epilepsy. Esquirol's ${ }^{94}$ view that all manner of mental reactions may accompany epilepsy remains true, despite the fact that we are looking at a selected group of patients for possible surgical intervention. Vasquez ${ }^{95}$ considered that no specific mental state identified the patient with temporal lobe epilepsy. According to Fenton, ${ }^{74}$ the interictal psychiatric disorders of epilepsy manifest the same range of mental state and behavioural phe- 
nomena as the functional psychiatric syndromes in the absence of epilepsy. Himmellhoch ${ }^{96}$ argued that epileptic patients present with atypical behavioural syndromes, which may not be comparable with the nonepilepsy associated psychiatric disorders. Whereas this may be true in a few patients with a severe neurological and psychiatric disorder, as evidenced in some of the older medical literature, there is not much evidence to generalise it for all psychiatric disturbances seen in epileptic patients. The present study was not specifically designed to test this hypothesis. However, an assessment of a selected group of candidates for surgery for epilepsy shows that a wide range of psychiatric morbidity is present.

1 Horsley V. Brain - Surgery. Br f Hosp Med 1886;2:676-75. Engel J Jr, ed. Surgical treatment of the epilepsies. New York: Raven Press, 1987.

3 Fenwick P, Dietrich B, Caplan R, Ferguson S, Savard G, Victoroff J. Presurgical psychiatric assessment. In: Engel $\mathrm{Jr}$, ed. Surgical treatment of the epilepsies. New York: Raven Press, 1993:273-90.

4 Hill D, Pond DA, Mitchell W, et al. Personality changes following temporal lobectomy for epilepsy. Fournal of following temporal lobectomy

5 Simmel ML, Counts S. Clinical and pyschological results of anterior temporal lobectomy in patients with psychomotor epilepsy. In: Baldwin M, Bailey $P$, eds Temporal lobe epilepsy: a colloquium. Springfield: Charles C Thomas, 1958:530-50.

6 Taylor DC. Mental state and temporal lobe epilepsy: a correlative account of a hundred patients treated surgically. Epilepsia 1972;13:727-65.

7 Taylor DC. Psychiatric and social issues in measuring the input and outcome of epilepsy surgery. In: Engel J Jr, ed. Surgical treatment of the epilepsies. New York: Raven Press, 1987:485-503.

8 Jensen I. Temporal lobe epilepsy, social conditions and rehabilitation after surgery. Acta Neurol Scand 1976;54: $22-44$.

9 Taylor DC, March SM. Implications of long-term followup studies in epilepsy: with a note on the cause of death. In: Penry JK, ed. Epilepsy, the eighth international symposium. New York: Raven Press, 1977:27-34.

10 Jensen I, Larsen JK. Mental aspects of temporal lobe epilepsy. Follow-up of 74 patients after resection of a temporal lobe. 7 Neurol Neurosurg Psychiatry 1979;42: 256-65.

11 Walker AE, Blumer D. Behavioral effects of tempora lobectomy for temporal lobe epilepsy. In: Blumer D, ed Psychiatric aspects of epilepsy. Washington, DC: American Psychiatric Press, 1984:295-323.

12 Bladin PF. Psychosocial difficulties and outcome after temporal lobectomy. Epilepsia 1992;33:898-907.

13 Perez MM, Trimble MR, Murray NMF, Reider I Epileptic psychosis: an evaluation of PSE profiles. $\mathrm{Br} \mathcal{F}$ Psychol 1985;146:155-63.

14 Trimble MR. The psychoses of epilepsy. New York: Raven Press, 1991.

15 Schmitz B, Wolfe P. Psychoses in epilepsy. In: Devinsky O, Theodore WH, eds. Epilepsy and behavior. New York: Wiley-Liss, 1991:97-128.

16 Sherwin J. Clinical and EEG aspects of temporal lobe epilepsy with behavior disorder: the role of cerebral dominance. In: Blumer D, Levin K, eds. McLean Hospital foumal 1977; (special issue, June): 40-50.

17 Sherwin I. Psychosis associated with epilepsy: significance of the laterality of the epileptogenic lesion. 7 Neurol Neurosurg Psychiatry 1981;44:83-5.

18 Blumer D, Montouris G, Hermann B. Psychiatric morbidity in seizure patients on a neurodiagnostic monitoring unit. $\mathcal{F}$ Neuropsychiatry clin neurosci 1996 (in press).

19 Robertson MM, Trimble MR. Depressive illness in patients with epilepsy: a review. Epilepsia patients with
1983;22:515-24

20 Mendez MF, Cummings JL, Benson DF. Depression in epilepsy. Arch Neurol 1986;43:766-70.

21 Blumer D. Epilepsy and disorders of mood. In: Smith DV Treiman DM, Trimble MR, eds. Neurobehavioral problems in epilepsy. New York: Raven Press, 1991:185-95.

22 Betts TA. Depression, anxiety and epilepsy. In: Reynolds $\mathrm{EH}$, Trimble MM, eds. Epilepsy and psychiatry. Edinburgh: Churchill Livingstone; $1981: 60-71$.

23 Manchanda $R$, Schaefer B, MCLan RS, Blume WT. Interictal psychiatric morbidity and focus of epilepsy in treatment-refractory patients admitted to an epilepsy unit. Ain F Psychiatry 1992;149:1096-8.

24 Goldberg DP. Manual of the general health questionnaire. Slough: NFER-Nelson, 1972

25 Manchanda R, Schaefer B, McLachlan R, Blume W. Relationship of site of seizure focus to psychiatric morbidity. F Epilepsy 1995;8:23-8.

26 Commission on Classification and Terminology of the
International League Against Epilepsy: Proposal for revised clinical and electro-encephalographic classification of epileptic seizures. Epilepsy 1981;22:489-501.

27 American Psychiatric Publication. Diagnostic and statistical manual of mental disorders. 3rd ed, rev. Washington, DC: APA, 1987.

28 Wing JK, Cooper JF, Sartorius N. The description of psychiatric symptoms. Cambridge: Cambridge University Press, 1974 .

29 Cooper JE, Kendell RE, Gurland BJ, Sharpe L, Copeland JRM, Simon R. Psychiatric diagnosis in New York and London. London: Oxford University Press, 1972.

30 World Health Organisation. The intermational pilot study of schizophrenia. Geneva: WHO, 1973.

31 Manchanda R, Hirsch S. Rating scales for clinical studies on schizophrenia. In: Bradley PB, Hirsch SR, eds. The psychopharmacology and treatment of schizophrenia. New psychopharmacology and treatment of schizophrom
York: Oxford University Press, 1986:234 62.

32 Wing JK, Nixon JM, Mann SA, Leff JP. Reliability of the PSE (ninth edition) used in a population study. Psychol Med 1977;7:505-16.

33 Knights A, Hirsch SR, Platt SD. Measurement of clinical change as a function of brief admission to hospital: a controlled study. Br F Psychiatry 1980;137:170-80.

34 Pond DA, Bidwell BH. A survey of epilepsy in fourteen general practices, II: social and psychological aspects. Epilepsia 1959;1:285-99.

35 Gudmundsson G. Epilepsy in Iceland: a clinical and epidemiological investigation. Acta Neurol Scand Suppl 1966;25:1-124.

36 Edeh J, Toone B. Relationship between interictal psychopathology and the type of epilepsy. $B r f \mathcal{F}$ Pychiatry 1987;151:95-101.

37 Gibbs FA. Ictal and non-ictal psychiatric disorders in temporal lobe epilepsy. $\mathcal{F}$ Nero Ment Dis 1951;11:522-8.

38 Small JG, Milstein V, Stevens JR. Are psychomotor epileptics different? a controlled study. Arch Neurol 1962;7 $187-94$

39 Stevens JR. Psychiatric implications of psychomotor epilepsy. Arch Gen Psychiatry 1966;14:461-71.

40 Gureje $O$. Interictal psychopathology in epilepsy: prevalence and pattern in a Nigerian clinic. Br $\mathcal{F}$ Psychiatm 1991;158:700-5.

41 Victoroff J. DSM-III-R psychiatric diagnoses in candidates for epilepsy surgery: lifetime prevalences. Neuropsychiatry, Neuropsychology and Behavioral Neurology 1994;7:87-97.

42 Hill JD. Psychiatric disorders of epilepsy. Medical Press 1953;20:473-5.

43 Pond DA. Psychiatric aspects of epilepsy. Foumal of the Indian Medical Profession 1957;3:1441-51.

44 Slater E, Beard AW, Glithero E. The schizophrenia-like psychoses of epilepsy. Br f Psychiatry 1963;109:95-150.

45 Trimble MR. The psychoses of epilepsy. New York: Raven Press, 1991:145-9.

46 Bear DM, Fedio P. Quantitative analysis of interictal behavior in temporal lobe epilepsy. Arch Neurol 1977;34:454-67.

47 Waxman SG, Geschwind N. The interictal behavior syndrome of temporal lobe epilepsy. Arch Gen Psychiatry 1975;32:1580-8.

48 Trimble MR. Epilepsy and behavior. Epilepsy Res 1991; 10:71-9.

49 Rodin EA, Dejong RN, Waggoner WR, Bagchi BK. Relationship between certain forms of psychomotor epilepsy and schizophrenia. Archives of Neurology and Psychiatry 1957;77:449-63.

50 Vislie H, Henrikson GF. Psychiatric disturbances in epilepsy. In: Lorentz de Haas AM, ed. Lectures in epilepsy. Amsterdam: Elsevier, 1958

51 Mirksy AF, Primac DW, Ajmone Marson C, Rosvold HC, Stevens JR. A comparison of the psychological test performances of patients with focal and non-focal epilepsy. Exp Neurol 1960;2:75-89.

52 Guerrant J, Anderson WW, Fischer A, Weinstein MR, Janos RM, Deskins A. Personality in epilepsy. Springfield, Ill: Charles C Thomas, 1962 .

53 Small JG, Small IF, Hayden MP. Further psychiatric investigations in patients with temporal and non-temporal lobe epilepsy. Am F Psychiatry 1966;123:303-10.

54 Juul-Jensen P. Epilepsy: a clinical and social analysis of ,020 adult patients with epileptic seizures. Acta Neurol Scand 1964;40(suppl) 15:1-148.

55 Stevens JR. Psychomotor epilepsy and schizophrenia: a common anatomy? In: Brazier M, eds. Epilepsy-its phecommon anatomy? In: Brazier M, eds. Epilepsy-its phe
nomena in man. New York: Academic Press, 1973.

56 Standage KF. Schizophreniform psychosis among epileptics in a mental hospital. Br f Psychiatry 1973;123:231-2.

57 Gibbs EL, Gibbs FA, Fuster B. Psychomotor epilepsy Archives of Neurology and Psychiatry 1948;60:331-9.

58 Pond DA, Bidwell BH. A survey of epilepsy in fourteen general practices-II (Social and psychiatric aspects). Epilepsia 1960;1:285-99.

59 Nuffield EJA. Neurophysiology and behavior disorders in epileptic children. Fournal of Mental Science 1961; 107:428-58

60 Slater E, Beard AW, Glithero E. The schizophrenia-like psychosis of epilepsy. Br F Psychiatry 1963;109:95 150.

61 Glaser GH. The problem of psychotic behaviour in temporal lobe epilepsy. Epilepsia 1964;5:271-8.

62 Preston DW, Atack EA. Temporal lobe epilepsy: a clinical study of 97 cases. Can Med Assoc $\mathcal{7}$ 1964;91:1256-9.

63 Graham P, Rutter M. Organic brain dysfunction and child psychiatric disorders. BMF 1968;3:695-700. 
64 Flor-Henry P. Schizophrenia-like reactions and affective psychosis associated with temporal lobe epilepsy: aetiological factors. Am f Psychiatry 1969;126:400-4.

65 Flor-Henry P. Ictal and inter-ictal psychiatric manifestations in epilepsy, specific or non-specific? A critical review of some of the evidence. Epilepsia 1972;13:773-83.

66 Flor-Henry P. Psychosis, neurosis and epilepsy. $\mathrm{Br} f$ Psychol 1974;124:144-50.

67 Bruens JH. Psychosis in epilepsy. Psychiatr Neurol Neurochir 1971;74:175-92.

68 Shukla GD, Srivastava BC, Katiyak VJ, Mohan PK. Psychiatric manifestations in temporal lobe epilepsy: a Psychiatric manifestations in temporal lobe ep
controlled study. Br $\mathcal{A}$ Psychiatry 1979;135:411-7.

69 Sherwin I. Differential psychiatric features in epilepsy; relationship to lesion laterality. Acta Psychiatr Scand 1984; 69(suppl 313):92-103.

70 Bash KW, Mahnig P. Epileptiker in der psychiatrischen klinik. Von der Dammerattack E. zur Psychose. Eur Arch Psychiatry Neurol Sci 1984;234:237-49.

71 Bruens JH. Psychoses in epilepsy. In: Vin Ken PJ, Bruyn $\mathrm{GW}$, eds. Handbook of clinical neurology. Vol 15. Amsterdam: North Holland, 1974:593-610.

72 Helmchen $\mathrm{H}$. Zerebrale Bedingun gskonstellationen psychopathologischer syndrome bei epileptikern. In: Helmchen $\mathrm{H}$, Hippius $\mathrm{H}$, eds. Entwicklungstendenzen biologischer Psychiatrie. Stuttgart: Thieme, 1975: 125-48.

73 Kohler GK. Zur Einteilung der Psychosen bei Epilepsie. Zum Begritt Psychosen bei epilepsie bzw epileptische
psychosen. In: Wolfe P, Koehler GK, eds. Psychopsychosen. In: Wolfe P, Koehler GK, eds. Psychopathologische und pathogenetische probleme psychon
drome bei Epilepsie. Bern: Huber, 1980:11-8.

74 Fenton GW. Psychiatric disorders in epilepsy: classification and phenomenology. In: Reynolds EH, Trimble MR, eds. Epilepsy and psychiatry. Edinburgh: Churchill Livingstone, 1981:12-26.

75 Stevens JR. Psychosis and the temporal lobe. In: Smith $\mathrm{DB}$, Treiman DM, Trimble MR, eds. Advances in neurology. Vol 55. Neurobehavioral problems in epilepsy. New York: Raven Press, 1991:79-96.

76 Gasteaut H. Etude electronique des episodes psychotiques surviennent chez les epileptiques en dehors des crises cliniques. Rev Neurol 1956;95:587-616.

77 Mignone WB. Psychological disturbance in African Tanzanian epileptics. Trop Geogr Med 1970;11: 345-59.

78 Standage KF, Fenton GW. Psychiatric symptom profiles of patients with epilepsy: a controlled investigation. Psychol patients with epileps
Med $1975 ; 5: 152-60$

79 Sengoku A, Yagi K, Seino M, Wada T. Risk of occurrence of psychoses in relation to the types of epilepsies and epilep- tic seizures. Folia Psychiatrica et Neurologica fapanica 1983;37:221-6

80 Schmitz B. Psychosis and Epilepsy: The link to the temporal lobe. In: Trimble M, Bolwig T, eds. The temporal lobes and the limbic system. Weightson Biomedical Publishing Ltd, 1992:149-67.

81 Schmitz B. Psychosen bei Epilepsie [thesis]. Berlin: Freie Universitat, 1988.

82 Ounsted C. Aggression and epilepsy. Rage in children with temporal lobe epilepsy. F Psychosom Res 1969;13:237-42.

83 Rodin EA, Katz M, Lennox K. Differences between patients with temporal lobe seizures and those with other patients with temporal lobe seizures and th
forms of attacks. Epilepsia 1976;17:313-20.

84 Herman BP, Dikmen S, Schwartz MS, Karnes WE. Psychopathology in TLE patients with ictal fear: a quantitative investigation. Neurology 1982;32:7-11.

85 Lindsay J, Ounsted C, Richard P. Long-term outcome in children with temporal lobe seizures. III. Psychiatric aspects in childhood and adult life. Dev Med Child Neurol 1979;21:630-6.

86 Currie S, Heathfield KWG, Henson RA, Scott DF Clinical course and prognosis of temporal lobe epilepsy: a survey of 666 patients. Brain 1971;94:173-90.

87 Kogeorgos J, Fonagy P, Scott DF. Psychiatric symptom patterns of chronic epileptics attending a neurological clinic: a controlled investigation. Br $\mathcal{F}$ Psychiatry 1982; 140:236-43.

88 Victoroff J, Benson F, Grafton S, Engel J, Mazziotta J. Depression in complex partial seizure. Arch Neurol 1994; 51:155-63.

89 Anderson VE, Hauser WA, Rich SS. Genetic heterogeneity in the epilepsies. In: Delgado-Esueta AVC, Ward AA, Woodbury DM, Porter RJ, eds. Advances in neurology. Vol 44. New York: Raven Press, 1988:59-75.

90 Rutter M, Graham P, Yule W. A neuropsychiatric study in childhood. Clinics in Developmental Medicine Nos 35/36. London: SIMP with Heinemann Medical, 1971.

91 Hoare P. Psychiatric disturbance in the families of epileptic children. Dev Med Child Neurol 1984;26:14-9.

92 Bagley C. The social psychology of the child with epilepsy. London: Routledge and Kegan Paul, 1971.

93 Anderson E, Barton R. Epilepsy-a family burden? Clinical Psychology Forum 1990;25:3-5.

94 Esquirol E. Des maladies mentales-medical, hygienique et medico-legal. Vol 2. Paris: Bailliere, 1838, 678;863.

95 Vasquez J. Epilepsies temporales et manifestations mentales, Union Med Can 1952;81:1062-8.

96 Himmellhoch JM. Major mood disorder disorders related to epileptic changes. In: Blumer D, ed. Psychiatric aspects of epilepsy. Washington, DC: American Psychiatric Press, 1984:271-94. 